\title{
ANALISIS VARIABEL-VARIABEL PENENTU CLEANLINESS FACTOR DAN PERFORMANCE FACTOR UNTUK MENINGKATKAN KINERJA KONDENSOR UNIT 1 PLTU SEKTOR ASAM-ASAM
}

\author{
${ }^{(1)}$ Muhammad Ashar, ${ }^{(2)}$ Sobar Ihsan, ${ }^{(3)} \operatorname{Irfan},{ }^{(4)}$ Slamet Ramadhan \\ ${ }^{(1)(2)}$ Prodi Teknik Mesin, ${ }^{(3)}$ Prodi Teknik Elektro, Fakultas Teknik, Universitas Islam \\ Kalimantan MAB \\ Jl. Adhiyaksa No. 2 Kayu Tangi, Banjarmasin \\ Email:muhammadashar94@gmail.com,sobar.uniska@gmail.com, \\ irfan9617@gmail.com, slametramadhan77@gmail.com
}

\begin{abstract}
ABSTRAK
Pemanatauan kierja kondensor PT. PLN Persero Sektor Asam-Asam pada keadaan operasi membuthkan nilai Cleanliness Factor dan Performance Factor. Analisis variabel-variabel yang menentukan Clinelines Factor dan Performance Factor diperlukan agar kinerjanya dapat ditingkatkan. Penelitian ini bertujuan untuk mendapatkan nilai Cleanlines Factor dan Performance Factor, mengetahui pengaruh perubahan beban terhadap Cleanlines Factor dan Performance Factor, mengetahui variabel-variabel mempengaruhi kinerja kondenser dan mencari solusi untuk meningkatkan performance kondensor. Nilai Cleanlines Factor didapatkan dari rasio perbandingan koefisien transfer panas total keadaan aktual terhadap koefisien transfer panas HEI sedangkan PF didapat dari rasio koefisien transfer panas total keadaan aktual terhadap koefisien transfer panas ASME. Data-data operasi menunjukkan bahwa nilai Cleanlines Factor dan Performance Factor meningkat seiring dengan meningkatnya beban pembangkitan listrik. . Hal ini membuktikan bahwa fouling bukan penyebab rendahnya nilai Cleanlines Factor dan Performance Factor. Variabel-variabel yang dianalisis yaitu suhu inlet cooling water (Tin), tekanan kondenser/back pressure $\left(\mathrm{P}_{\text {back }}\right)$ dan aliran volumetrik cooling water (Colling Water flow).
\end{abstract}

\section{Kata Kunci : Kondensor, Cleanliness Factor, Performance Factor}

\section{PENDAHULUAN}

Kondensor adalah salah satu jenis mesin penukar kalor (heat exchanger) yang berfungsi untuk mengkondensasikan fluida kerja. Pada sistem tenaga uap atau lebih tepatnya pada PLTU Sektor AsamAsam, fungsi kondensor adalah untuk mendinginkan atau mengkondensasikan uap keluaran turbin tekanan rendah dengan menggunakan air laut sebagai fluida pendinginnya sehingga dapat dipompakan kembali ke boiler. Pada sistem kondensor di pembangkit listrik terdapat alat bantu vacuum sistem (sistem vakum) yang biasanya berupa
Hogging Ejector dan Main Air Ejector. Perlu diketahui bahwasannya vakum kondensor terbentuk oleh proses di kondensasi kondensor dan bukan oleh peralatan bantu vacuum system (vacuum pump atau Main Air Ejector). Fungsi Main Air Ejector ini adalah mengekstrak atau membuang udara atau gas-gas lainnya di dalam kondensor dan membuangnya ke atmosfer. Sistem alat bantu vakum ini juga berfungsi sebagai pembuat vakum saat start unit turbin uap. Setelah normal operasi dan terdapat uap yang masuk ke turbin maka proses vakum kondensor diambil alih oleh 
proses kondensasi uap menjadi air (air kondensat). Unjuk kerja kondenser ditunjukkan oleh nilai cleanliness factor dan performance factor. Nilai ini sangat dipengaruhi oleh banyaknya panas yang dapat ditransfer dari steam ke air pendingin. Semakin besar transfer panas aktual yang terjadi (dibandingkan keadaan bersihnya), semakin besar pula nilai cleanliness factor dan performance factor. Tranfer panas tersebut sangat dipengaruhi oleh beberapa hal, di antaranya keberadaan fouling dan udara luar dapat menurunkan nilai cleanliness factor dan performance factor. Dengan turunnya nilai cleanliness factor dan performance factor, maka efisiensi pembangkitan listrik menjadi turun. Dengan mengetahui cleanliness factor dan performance factor, diharapkan pemantauan dan pemeliharaan kondenser akan lebih mudah dilakukan dan dengan waktu yang tepat. Selain itu, dengan menganalisis distribusi nilai cleanliness factor dan performance factor pada beberapa keadaan operasi, diharapkan perbaikan dapat dilakukan agar efisiensi plant meningkat.

\section{METODE PENELITIAN}

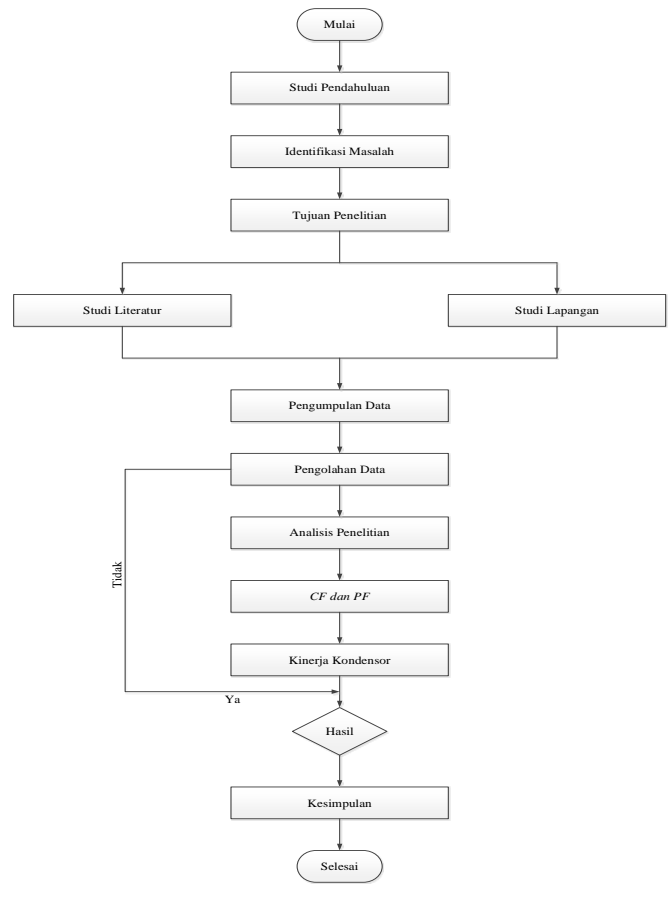

\section{HASIL DAN PEMBAHASAN}

Tabel 1 Data Kondensor Untuk Perhitungan CF dan PF

\begin{tabular}{|c|c|c|c|}
\hline Keterangan & Lambang & Data Kondensor & Satuan \\
\hline Diameter Luar Tube & $d_{0}$ & 0,875 & in \\
\hline Diameter Dalam Tube & $\mathrm{d}_{\mathrm{i}}$ & 0,8191 & in \\
\hline Panjang Efektif Tube & $\mathrm{L}$ & 42,781632 & $\mathrm{ft}$ \\
\hline Jumlah Tube & $\mathrm{N}$ & 12776 & Tube \\
\hline Jumlah Pass & $\mathrm{N}_{\text {pass }}$ & 2 & - \\
\hline Faktor Koreksi Material & $F_{m}$ & 0,86 & - \\
\hline Konduktifitas Material Tube & $\mathrm{K}_{\mathrm{m}}$ & 86 & Btu/h.ft.F \\
\hline Percepatan Gravitasi & g & 417000000 & $\begin{array}{c}\mathrm{ft} .1 \mathrm{bm} / \mathrm{h} 2.1 \mathrm{~b} \\
\mathrm{f}\end{array}$ \\
\hline Suhu Shell & $\mathrm{T}_{\mathrm{v}}$ & 111,63 & $F$ \\
\hline Aliran Volumetrik & $\mathrm{G}$ & 92066,3 & GPM \\
\hline Temperatur Inlet Tube & $\mathrm{T}_{\text {in }}$ & 83,18 & $F$ \\
\hline Temperatur Oulet Tube & $\mathrm{T}_{\text {out }}$ & 104,14 & $\mathrm{~F}$ \\
\hline Temperatur Tube Rata-Rata & $\mathrm{T}_{\text {bulk }}$ & 93,66 & $\mathrm{~F}$ \\
\hline \multirow[t]{2}{*}{ Tekanan Kondensor } & $\mathrm{P}_{\text {back Pressure }}$ & 0,092125 & barA \\
\hline & & 1,336164816 & Psi \\
\hline Steam Exhaust Flow & $\mathrm{W}$ & 1001485,88 & $1 / \mathrm{bh}$ \\
\hline Daya Generator & & 65 & MW \\
\hline
\end{tabular}

Nilai PF lebih kecil dari pada CF disebabkan karena koefisien $\mathrm{U}_{\mathrm{HEI}}$ adalah nilai transfer panas keseluruhan tube bundle, sedangkan koefisien $\mathrm{U}_{\mathrm{ASME}}$ yang dihitung dari risestensi termal adalah nilai single tube.

Tabel 2 dan 3 menyajikan 2 keadaan kondenser : desain kondenser dan kondenser unit 1 pada performance test yang dilakukan pada bulan April 2018. Data yang digunakan dibagi menjadi 2 , yaitu: variabel tetap yang merupakan variabel yang tidak berubah karena merupakan spesifikasi utama kondenser dan variabel berubah yang didapat dari performance test.

Tabel 2 Data Desain Kondensor dan Data Kondensor Unit 1

\begin{tabular}{|c|c|c|c|c|}
\hline \multicolumn{4}{|c|}{ Variabel Tetap } & Satuan \\
\hline Keterangan & Lambang & Design & April 2018 & \\
\hline Diameter Luar Tube & $\mathrm{d}_{0}$ & 0,875 & 0,875 & in \\
\hline Diameter Dalam Tube & $\mathrm{d}_{\mathrm{i}}$ & 0,8191 & 0,8191 & in \\
\hline Panjang Efektif Tube & $\mathrm{L}$ & 42,781632 & 42,781632 & $\mathrm{ft}$ \\
\hline Jumlah Tube & $\mathrm{N}$ & 12776 & 12776 & tube \\
\hline Jumlah Pass & $\mathrm{N}_{\text {pass }}$ & 2 & 2 & - \\
\hline Tipe 22BWG dg SS316 & $F_{m}$ & 0,86 & 0,86 & - \\
\hline Konduktivitas Material Tube & $k_{m}$ & 8,6673 & 8,6 & Btu/h.ft.F \\
\hline Percepatan Gravitasi & $\mathrm{G}$ & 417000000 & 417000000 & $\mathrm{Ft} / \mathrm{lbm} / \mathrm{h} 2 / \mathrm{lbf}$ \\
\hline \multicolumn{4}{|c|}{ Variabel Bebas } & Satuan \\
\hline Keterangan & Lambang & Design & April 2018 & \\
\hline Suhu Shell & $\mathrm{T}_{\mathrm{v}}$ & 107,86 & 111,63 & $\bar{F}$ \\
\hline Steam Inlet & & 343060 & & $\mathrm{Kg} / \mathrm{h}$ \\
\hline Aliran Volumetrik & G & 2.24 & 2.24 & GPM \\
\hline Temperatur Inlet Tube & $\mathrm{T}_{\text {in }}$ & 36.6 & 83,18 & $\mathrm{~F}$ \\
\hline Temperatut Outlet Tube & $\mathrm{T}_{\text {out }}$ & 47.5 & 104,14 & $\mathrm{~F}$ \\
\hline Temperatur Tube Rata-Rata & $T_{\text {bulk }}$ & 90,95 & 93,66 & $\mathrm{~F}$ \\
\hline Tekanan Kondensor & $\mathrm{P}_{\text {back pressure }}$ & 0,0826589 & 0.092125 & $\mathrm{BarA}$ \\
\hline & & 1,1988701 & 1,3361648 & PsiA \\
\hline Steam Exhaust Flow & $\mathrm{W}_{\mathrm{EX}}$ & 756317,82 & 1001485,8 & $1 \mathrm{~b} / \mathrm{h}$ \\
\hline Iterasi Nilai Awal & $T_{w o}$ & 102,63652 & 105,60726 & $\mathrm{~F}$ \\
\hline Iterasi Nilai Akhir & $T_{W o}$ & 102,63652 & 105,60726 & F \\
\hline Daya Generator & & 55 & 65 & MW \\
\hline
\end{tabular}


Tabel 3 Perhitungan Untuk Desain Kondensor Unit 1

\begin{tabular}{|c|c|c|c|c|c|}
\hline \multirow[b]{2}{*}{ No } & \multicolumn{4}{|c|}{ Perhitungan Utama } & \multirow[t]{2}{*}{ Satuan } \\
\hline & Keterangan & Lambang & Deaign & $\begin{array}{c}\begin{array}{c}\text { Kondensor } \\
\text { Unit 1 }\end{array} \\
\end{array}$ & \\
\hline 1 & Luas Permukaan Transfer Panas & A & 125207,09 & 125207,09 & $\mathrm{ft}^{2}$ \\
\hline 2 & Luas Aliran Air Pendingin & $A_{4}$ & 23,375782 & 23,375782 & $\mathrm{ft}^{2}$ \\
\hline 3 & Massa Jenis Air & $\rho$ & 62,251304 & 62,225324 & $16 \mathrm{~m} / \mathrm{ft}^{2}$ \\
\hline 4 & Kalor Jenis Air & $C p$ & 0,9981472 & 09980668 & $\operatorname{Bta}(\operatorname{lom} F)$ \\
\hline 5 & Aliran Massa & $\mathrm{m}$ & 39164194 & 46015005 & $1 b m / h$ \\
\hline 6 & Kecepatan Aliran Air Pendingin & $\mathrm{V}$ & 7,4760482 & 8,7874659 & $\mathrm{ft} / \mathrm{s}$ \\
\hline 7 & LMTD & LMTD & 14,715949 & 15,705323 & $F$ \\
\hline 8 & Kalor Yang di Transfer & Q & 781047289 & 962610034 & Btuh \\
\hline 9 & Koefisien Transfer Panas & $\mathrm{U}_{\text {etf }}$ & 423,89676 & 489,52466 & $\operatorname{Bta}\left(\mathrm{At}^{2} \cdot \mathrm{h} \cdot \mathrm{F}\right)$ \\
\hline \multirow[b]{2}{*}{ No } & \multicolumn{4}{|c|}{ Perhitungen HEI } & Satuan \\
\hline & Keterangan & Lambang & Design & \begin{tabular}{|c|} 
Kondensor \\
Unit 1
\end{tabular} & \\
\hline 1 & $\mathrm{U}_{\text {MSE }}$ & $\mathrm{U}_{\mathrm{M} h \mathrm{SI}}$ & 721,83839 & 778,3173 & $\mathrm{Btu}\left(\mathrm{f}^{2} \cdot \mathrm{hF}\right)$ \\
\hline 2 & Faktor Koreksi Temperatur HEI & $F_{W}$ & 1,0478918 & 1,054708 & - \\
\hline 3 & Faktor Koreksi Material HEI & $F_{n}$ & 0,86 & 0,86 & - \\
\hline 4 & Koefisien Transfer Pamas HEI & $\mathrm{U}_{\mathrm{ant}}$ & 650,51136 & 705,9721 & \\
\hline 5 & Cleanliness Factors & $\mathrm{CF}$ & 65,16362 & 69,34050 & $\%$ \\
\hline \multirow[b]{2}{*}{ No } & \multicolumn{4}{|c|}{ Perhitungan Resistensi Termal } & Satuan \\
\hline & Keterangan & Lambeng & Design & \begin{tabular}{|c|}
$\begin{array}{c}\text { Kondensor } \\
\text { Unit } 1\end{array}$ \\
\end{tabular} & \\
\hline 1 & Resestensi Dinding Tube & $R_{w}$ & 0,0002776 & 0,0002798 & $F /($ Btuh $h) f^{2}$ \\
\hline 2 & \begin{tabular}{|l|} 
Viskositas \\
\end{tabular} & $\mu$ & 1,9036956 & 1,8252381 & $\operatorname{lom} / \mathrm{h} \mathrm{ft}$ \\
\hline 3 & Massa Jenis & $p$ & 62,251304 & 62,093898 & $16 \mathrm{~m} / \mathrm{ft}^{3}$ \\
\hline 4 & Kalor Jenis & $\mathrm{Cp}$ & 0,9979563 & 0,9979685 & Bta $(\operatorname{lom} F)$ \\
\hline 5 & Konduktivitas & $\mathrm{k}$ & 0,3786761 & 0,3720852 & Bta (h.f.F) \\
\hline 6 & Kecepatan & $\mathrm{V}$ & 7,4760482 & 8,7874659 & $\mathrm{ft} / 5$ \\
\hline 7 & Resistensi Sisi Air Pendingin & $R_{1}$ & 0,0005996 & 0,0005148 & $\mathrm{~F} /(\mathrm{Btu} / \mathrm{h}) \mathrm{f}^{2}$ \\
\hline 8 & Temp. Kondensor Rata-Rata & $T_{\varepsilon}$ & 105,24826 & 108,61863 & $F$ \\
\hline 9 & Konduktivitas Kondensat & $\mathrm{k}_{\mathrm{f}}$ & 0,3786761 & 0,3805184 & BtuhftF \\
\hline 10 & Percepatan Gravitasi & $\mathrm{g}$ & 417000000 & 417000000 & fft $1 \mathrm{bm} / \mathrm{h}^{2} . \mathrm{Ibf}$ \\
\hline 11 & Kalor Laten Kondensasi & & 1032,6498 & 1030,4671 & Btullom \\
\hline 12 & Viskositas Lapisan Kondengat & & 1,5389091 & 1,4698657 & $\mathrm{lom} / \mathrm{fth}$ \\
\hline 13 & Diameter Luar Tube & $D_{a}$ & 0,0729166 & 0,0729166 & ft \\
\hline 14 & $\Delta \mathrm{T}=\mathrm{T}_{\mathrm{v}}-\mathrm{T}_{\mathrm{WD}}$ & $\Delta \mathrm{T}$ & 5,2234709 & 6,0227324 & $F$ \\
\hline 15 & Massa Jenis & $p$ & 61,938265 & 61,892325 & $1 \mathrm{lom} / \mathrm{ft}^{3}$ \\
\hline 16 & Koeff Transfer Panas Sisi Shell & $\mathrm{h}_{\mathrm{s}}-\mathrm{LH}$ & 2550,0049 & 2496,0669 & Btuh $\mathrm{ft}^{2} F$ \\
\hline 17 & Koeff Transfer Panas Sisi Shell & $h_{\mathrm{l}}-\mathrm{MF}$ & 3254,2736 & 0,0004006 & Btuh $\mathrm{ft}^{2} \mathrm{~F}$ \\
\hline 18 & \begin{tabular}{|l|} 
Resistensi Fouling \\
\end{tabular} & $R_{t}$ & 0 & 0 & $F(\mathrm{Btu} / \mathrm{h}) \cdot \mathrm{f}^{2}$ \\
\hline 19 & Koef. Tranafer Panas ASME-LH & $\mathrm{U}_{\mathrm{ASMI}}$ & 787,69228 & 836,56890 & $B \operatorname{tal}\left(\mathrm{At}^{2}, h . F\right)$ \\
\hline 20 & Koef. Transfer Panas ASME-MF & $\mathrm{U}_{\mathrm{ASM}}$ & 844,12162 & 888,43842 & $\operatorname{Bta}\left(\mathrm{At}^{2} \cdot \mathrm{h} . \mathrm{F}\right)$ \\
\hline 21 & Performance Factors LH & $\mathrm{PF}_{1}$ & 53,81502 & 58,515762 & $\%$ \\
\hline 22 & Performance Factors MF & $\mathrm{PF}_{2}$ & 50,2175 & 55,099448 & $\%$ \\
\hline
\end{tabular}

Hasil perhitungan pada berbagai keadaan operasi untuk kondenser unit 1 terdapat pada Gambar 2, 3 dan 4. Analisis data dari lampiran ini ditunjukan pada grafik yang akan dibahas di bawah ini.

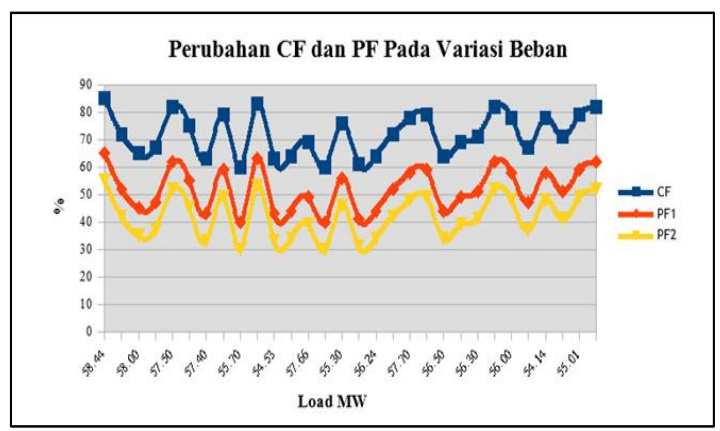

Gambar 2. Grafik Kondensor Unit 1, Perubahan CF dan PF Pada Variasi Beban

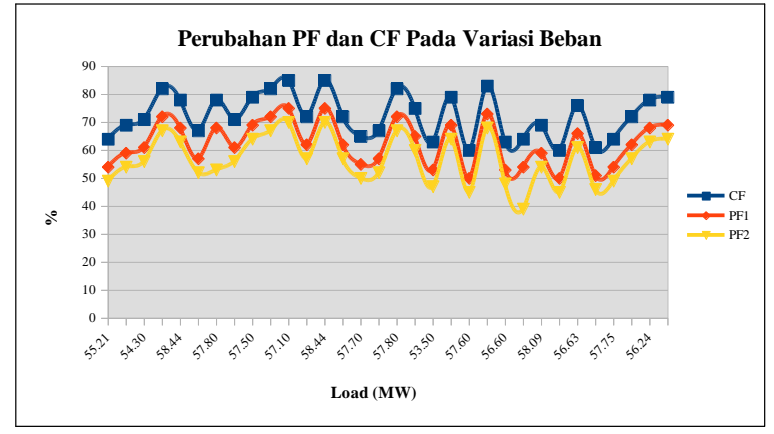

Gambar 3. Grafik Kondensor Unit 1, Perubahan CF dan PF Pada Variasi Beban

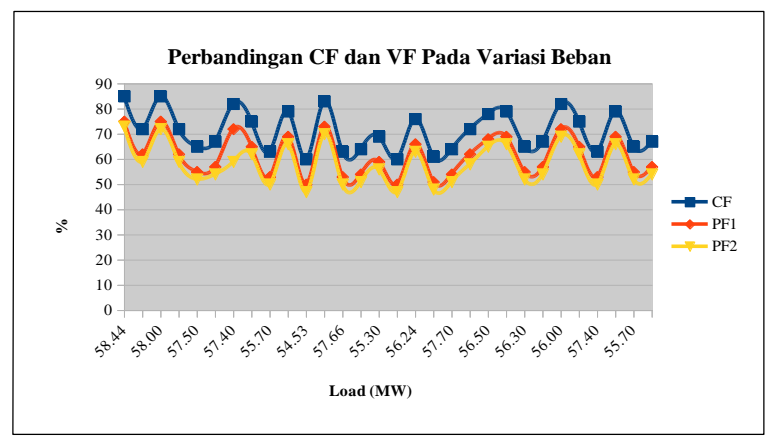

Gambar 4. Grafik Kondensor Unit 1, Perubahan CF dan PF Pada Variasi Beban

Dari Grafik hasil penelitian ini menyatakan bahwa kenaikan Cleanlines Factor dan Performance Factor berbanding lurus terhadap kenaikan beban., kenaikan Cleanlines Factor dan Performance Factor tetap berbanding lurus terhadap nilai beban. Hal ini membuktikan bahwa fouling bukanlah menjadi penyebab utama yang menyebabkan rendahnya nilai Cleanlines Factor dan Performnace Factor. Dengan kata lain, jika suatu kondenser uap tanpa fouling sekalipun dapat memiliki nilai Cleanline Factor dan Performance Factor yang rendah.

1) Pengaruh aliran cooling water

Berikut ini adalah pengaruh aliran cooling water terhadap Cleanlines Factor jika keempat variabel lainnya tetap. Grafik Gambar 5 ditinjau secara teoritis berdasarkan perhitungan Cleanlines Factor. 


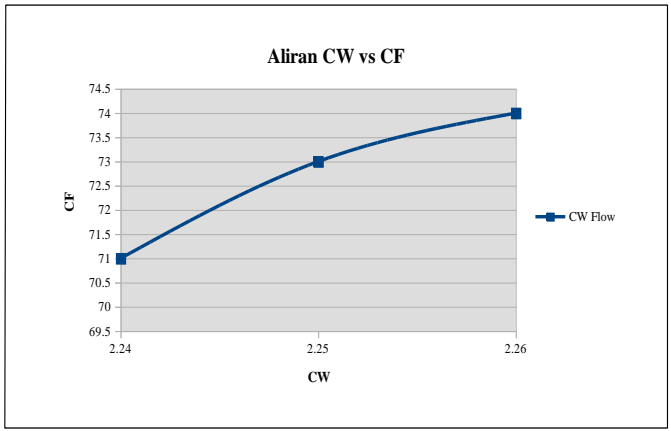

Gambar 5. Grafik Aliran Cooling Water vs CF

Dari grafik di atas dapat dilihat bahwa kenaikan Cleanlines Factor berbanding lurus terhadap kenaikan aliran dari cooling water. Hal ini di karena bertambahnya jumlah aliran air pendingin menyebabkan transfer panas lebih cepat sehingga uap akan terkondensasi lebih banyak dalam waktu yang relatif lebih pendek. Dengan kondisi suhu inlet air pendingin dan tekanan kondenser yang sama, kenaikan aliran cooling water mengakibatkan koefisien tranfer panas keadaan aktualnya lebih besar sehingga Cleanlines Factor meningkat.

2) Pengaruh suhu inlet dan outlet cooling water

Pada kondisi aktual, kenaikan suhu inlet air pendingin menyebabkan suhu outletnya meningkat. Grafik pada Gambar 6 menunjukkan bahwa kondisi operasi menyebabkan kenaikan $\mathrm{T}_{\text {out }}$ sebanding dengan kenaikan $\mathrm{T}_{\text {in. }}$. Hal ini berguna untuk mengimbangi jumlah kalor yang sama yang ditransfer pada kondisi suhu inlet yang berbeda namun keadaan transfer panasnya sama.

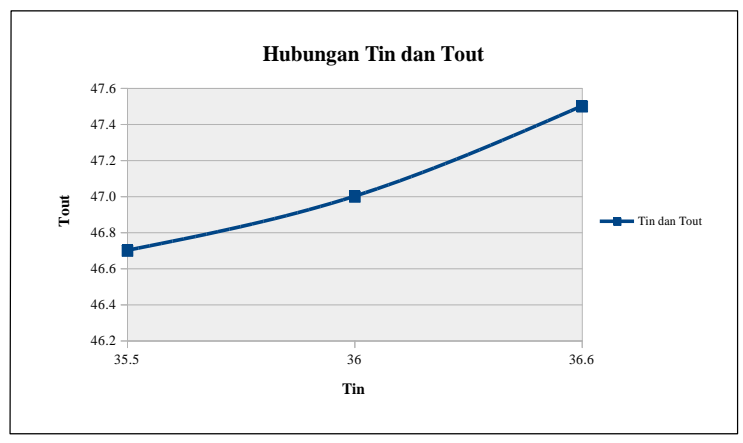

Gambar 6. Grafik Hubungan $\mathrm{T}_{\text {in }}$ dan $\mathrm{T}_{\text {out }}$
Dari Gambar 4.5 dapat disimpulkan bahwa gradiennya bernilai satu. Hal ini menunjukan perbandingan antara suhu inlet dan outlet adalah sama.

3) Pengaruh tekanan kondensor

Besarnya konsentrasi pada uap serta adanya kebocoran udara menyebabkan tekanan kondenser meningkat. Uap yang tidak dapat terkondensasi memiliki resistansi yang sangat besar dan memenuhi seluruh shell. Adanya uap-uap tersebut menghalangi transfer panas sehingga koefisien transfer panas efektifnya rendah. Dengan menurunnya nilai koefisien transfer panas efektif, maka cleanliness factor akan turun.

4) Pengaruh aliran steam

Pengaruh aliran uap yang masuk ke kondenser dalam perhitungan sebenarnya hanya berpengaruh pada perubahan nilai Performance Factor.

\section{KESIMPULAN}

Cleanlines Factor dan Performance Factor dapat digunakan sebagai ukuran kelayakan kondenser. Cleanlines Factor (standar HEI) dan Performance Factor (standar ASME) adalah ratio koefisien transfer panas efektif (aktual) terhadap koefisien transfer panas keadaan bersihnya. Untuk mengetahui pengaruh fouling, dilakukan analisis pengaruh perubahan beban terhadap Cleanlines Factor dan Performance Factor. Selain fouling, ada faktor-faktor dominan yang mempengaruhi Cleanlines Factor dan Performance Factor. Dengan menganalisis faktor-faktor tersebut diharapkan kinerja kondenser dapat ditingkatkan.

1. Cleanlines Factor maupun Performance Factor menunjukkan kenaikan ketika beban operasi mengalami peningkatan. Hal ini membuktikan bahwa fouling bukan 
penyebab utama atas rendahnya

nilai Cleanlines Factor dan

Performance Factor.

Kondisi operasi hanya memungkinkan untuk pengaturan aliran cooling water (CW flow), suhu inlet cooling water (Tin) dan tekanan kondenser/ back pressure (Pback). Tin dan interaksi Pback-Tin. Kenaikan Cleanlines Factor disebabkan oleh penurunan Pback dan kenaikan Tin. Data operasi menunjukkan bahwa Cleanlines Factor bergantung pada $\mathrm{P}_{\text {back }}$ dan Tin, namun tidak dapat dibuktikan bahwa interaksi Tin dan $\mathrm{P}_{\text {back }}$ menentukan nilai Cleanlines Factor.

\section{REFERENSI}

[1] Banks, D. (2008). An Introduction to Thermolgeology: Ground source heating and cooling.

[2] Berkeley;, \& King, E. F. (1859). This is a reproduction of a library book that was digitized by Google as part of an ongoing effort to preserve the information in books and make it universally accessible.

[3] Shah, R. K., \& Mueller, A. C. (2012). Heat Exchange. Ullmann's Encyclopedia of Industrial Chemistry, Vol. 21(October), 309338.

[4] Zhang, C., Sousa, A. C. M., \& Venart, J. E. S. (1993). The numerical and experimental study of a power plant condenser. J. Heat Transf., 115(March), 435-445.

[5] Fatkhurrahman, M. (2014). Analisis Kinerja Kondensor. Eksergi Jurnal Teknik Energi., 10(1), 29-34.

[6] Rotary, J. I., Safira, A., Lini, Z., Terbarukan, T. E., Teknik, J., Jember, P. N., ... Probolinggo, K. (2016). Penentuan Nilai Efektivitas Kondensor, 1(1), 1-7. 